\title{
Managing obesity and type 2 diabetes: the challenges of guideline implementation
}

David Haslam, GP, Watton-at-Stone

Physician in Obesity Management, Luton and Dunstable Hospital, Clinical Director, National Obesity Forum

Drugs in Context

DOI: http://dx.doi.org/10.7573/dic.212228

Citation: Haslam, D. Managing obesity and type 2 diabetes: the challenges of guideline implementation. Drugs in Context: e212228.

doi:10.7573/dic. 212228

Copyright: this is an open access article published under the terms of the Creative Commons License Deed (CG BY-NG-ND 3.0) which allows you to share, copy, distribute and transmit the work provided it is properly attributed. You may not use this work for commercial purposes. For further information on commercial use, contact publisher@justmedicalmedia.com or go to wrwr.drugsincontext.com/copyright.

NB: This article was originally published by CSF Medical Communications Ltd (CSF) in Drugs in Context 2008;4(2):191-2. Drugs in Context and all CSF copyrights were acquired by Just Medical Media Ltd in 2009. 


\title{
Managing obesity and type 2 diabetes: the challenges of guideline implementation
}

\author{
David Haslam, GP, Watton-at-Stone \\ Physician in Obesity Management, Luton and Dunstable Hospital, Clinical Director, National Obesity Forum
}

Obesity levels have reached epidemic proportions, and its comorbidities - heart disease, cancer, liver disease, stroke, sleep apnoea and premature death - are set to increase pro rata. Type 2 diabetes is the condition most closely linked with obesity, so much so that Sims and colleagues coined the term 'diabesity' in the 1970s, demonstrating the connection by overfeeding young men for 6 months such that their body mass index (BMI) increased to 28 , resulting in reversible rises in fasting concentrations of insulin, glucose and triglycerides, and impaired glucose tolerance. ${ }^{1}$ It is now accepted that almost $90 \%$ of cases of type 2 diabetes are due to excess weight. Conversely, the best way to treat diabetes is to lose weight - usually alongside oral hypoglycaemic agents (OHAs). To prove this point, gastric banding induces a near $100 \%$ resolution in type 2 diabetes. As diabetes is so often linked with overweight and obesity, weight management provides a 'Smart Bomb' approach. Weight loss also improves other crucial factors such as blood pressure and lipid profile, alongside glycaemic control.

The National Institute for Health and Clinical Excellence (NICE) has recently published Clinical Guideline 66: the management of type 2 diabetes $^{2}$ that highlights obesity as a major 'target for management' especially in certain ethnic minority groups. In addition, the NICE December 2006 'Obesity' guideline $43^{3}$ and the just published NICE technology appraisal 144: Rimonabant for the treatment of overweight and obese adults ${ }^{4}$ are both mindful of the risk of diabetes.

In the diabetes guideline, weight is a consideration in each step of the algorithm, emphasising not only the fact that excess weight is usually a major underlying factor in the development of type 2 diabetes, but also demonstrating awareness that drugs such as sulphonylureas, and, especially insulin, cause significant and harmful weight gain. For instance, the foremost contraindication to the first-line use of sulphonylureas is overweight, rather than the many other factors which deem them less suitable than metformin. At the other end of the algorithm, the therapeutic positioning of exenatide is after the use of traditional oral hypoglycaemic agents, in those people with significant body weight issues affecting health and quality of life.

More light was shed upon the optimum management of diabetes by three major studies presented at the American Diabetes Association Conference in San Francisco in June 2008: Action to Control Cardiovascular Risk in Diabetes (ACCORD), Action in Diabetes and Vascular Disease (ADVANCE) and the Veterans Affairs Diabetes Trial (VADT). Between them they condemned over-intensive and over-rapid reduction of $\mathrm{HbA}_{1 \mathrm{C}}$, by the use of drug therapy including insulin, as evidenced by the early abandonment of the intensive arm of ACCORD, and the revelation from VADT that significant hypoglycaemic episodes are the second biggest predictor of cardiovascular events, after age 
and the duration of diabetes. However, all three studies agreed that careful reduction of $\mathrm{HbA}_{1 \mathrm{C}}$ to lower targets is beneficial in reducing microvascular risk. No significant reduction in macrovascular risk was demonstrated in any of the trials, highlighting the importance of vigorous management of associated risk factors including obesity, cholesterol, smoking and blood pressure as the only proven ways of doing so. Intensive treatment to $\mathrm{HbA}_{1 \mathrm{C}}$ targets is shown only to make a difference if started early in the course of disease. In this context, the newer hypoglycaemic agents, as well as antiobesity pharmacological agents, if started early, come into their own, as they do not induce significant hypoglycaemia, thereby avoiding the pitfalls associated with insulin and insulin secretagogues; they reduce $\mathrm{HbA}_{1 \mathrm{C}}$ significantly, aiming for vigorous, but responsible lowering of $\mathrm{HbA}_{1 \mathrm{C}}$ to stricter targets.

Until the newer pharmacological agents to treat type 2 diabetes have been assessed by NICE, and antiobesity drugs are embraced in recognition of the improvements in cardiometabolic risk they are proven to induce, this new NICE clinical guideline 66 will be inadequate. Nevertheless, the guideline displays an encouraging acknowledgement of the issues relating to excess weight. The NICE clinical guideline 66 successfully reinforces the link between diabetes and excess weight, promotes the appropriate mutual first-line remedies, and will help to ensure that second-line pharmacological remedies are prescribed with excess weight in mind. But most importantly the guideline, alongside other emerging strands of evidence, accentuates the disparate profiles possessed by different patients, which require alternative management pathways. No guideline can be definitive in the face of vastly disparate phenotypes. An overweight diabetic patient demands different treatment than a lean one; a young one compared to their elderly counterpart; a newly diagnosed patient compared to one with long-standing illness. This guideline provides encouraging evidence that the obesity epidemic, which is driving the type 2 diabetes explosion, is being genuinely accredited and targeted as a fundamental factor in type 2 diabetes.

In practical terms, any person with diabetes associated with excess weight should be advised and assisted in weight-loss techniques. To ignore excess weight makes diabetes management futile, whereas appropriate treatment, inclusive of obesity management may succeed.

\section{REFERENCES}

1. Sims EAH, Danforth E, Horton ES et al. Endocrine andmetabolic effects of experimental obesity in man. Recent Prog Hormone Res 1973; 29: 457-96.

2. NICE clinical guideline 66 - Type 2 diabetes: the management of type 2 diabetes (update) 2008 www.nice.org.uk/

3. NICE clinical guideline 43 - Obesity 2006 www.nice.org.uk/

4. NICE technology appraisal guidance 144: Rimonabant for the treatment of overweight and obese adults 2008 www.nice.org.uk/ 